\section{LEEDS GENERAL INFIRMARY.}

CAEE OF 8UCCEBSFUL COMPREBSION OF THE FBXORAL ARTERY FOB TBADYCATIC POPLITEAL ANEURISM.

By T. P. Trate, Esq.

[Cominunicated by Jomx RooLstox, M.D., Low Harrogate.]

Wx. EALET, aged 32 years, coschman to Mr. Gandolfi, of Bawtry, Yorkshire, an active well-built man, in good bodily health, was admitted into the Leeds General Infirmary, September 8th, 1854, under the care of Mr. T. P. Teale, with aneurism of the popliteal artery. The tumour was about the size of a goose's egg, and circumscribed in character. The cause of the disease was an injury received in the beginning of April, in the same Jear, while unloading some luggage from a wagon. His leg slipped over the side rail of the rehicle, as far as the knee; and a heary box which he was lifting fell at the samo moment with oreat force upon that joint, crushing the popliteal space severely against the rail. He was taken home to bed; the parts were fomented for two or three days; and he then pent about his work as usual, a little stiffness only remaining. In July, the accession of pain, and increased difficulty in locomotion, caused him to examine the locality, and he found a tumour which had then attained a considerable size. He consulted a druggist at this time, who said he had "sprung a muscle", and gare him a liniment; but in Beptember, by the advice of a surgeon, he came to Leeds.

The tumour was of very regular form, and easily defined. Bruit loud and rough ; pulsation full and expansive, though very readily commanded by pressure on the femoral, when great part of the contents of the sac could be expressed.

September 13th. Compression was commenced by means of Signorini's tourniquet in Scarpa's triangle. The curxent was not completely arrested, but carefully controlled. The pressure was entirely remitted every night. No constitutional disturbance or local irritation resulted; he slept well, and enjoyed his food (the "common diet" of the hospital, but without beer). After three days, the management of the instrument was left to himself, and he kept a record of the time and interrals of its application.

Sept. 20th. There is a decided diminution in the size of the tumour, which removal of pressure does not much increase now. Pulsation and thrill less marked, though quite distinct.

Bept. 26th. Pulsation can neither be felt nor heard in the sac. A small artery can be detected passing across the tumour. The tourniquet is only applied occasionally, and with very long intervals.

Sept. 27th. The disease is evidently cured; and the tourniquet was entirely discontinued yesterday erening.

Oct. 1st. The leg was bandaged to prerent œdema, and he was allowed to get up and use the limb. No further treatment was adopted; and a few days after the above date, he was discharged cured.

The daily average of pressure was eleven hours.

REMaRKs. This was essentially a circumscribed aneurism, though traumatic; and the primary cause was, no doubt, laceration of the internal coats of the ressel, the external remaining continuous, though probably impaired considerably in resisting power. The result of treatment in traumatic aneurism, where a cure is effected, must always be more satisfactory, and the prognosis more encouraging; as we have not the diathesis of the patient to contend against. I have in memory several instances where, after cure of idiopathic popliteal aneurism, both by ligature and compression, sudden death has ensued with varied interval, from rupture of the thoracic aorta, consequent on aneurism of that vessel. The patient in one case survired until absorption of nearly the entire bodies of four contiguous vertebra, with the heads of the ribs, had occurred.

I am induced to send the details of the foregoing case, in consequence of the statement made by Mr. Dunstan, in the Assocratiox Jodksal for July 12th, that the case there published is the first of traumatic aneuriom of the popliteal artery cured by compression.

\section{Contributions to Climital Surgety:}

BY

Ourver Prabraton, Esq., Surgeon to the General Hospital, and Demonstrator of Anatomy in the Queen's College, Birmingham.

\section{No. III.}

ON CERTAIX FORYS OP OUTGROWTHS FBOX THE MUCO-CUTANEOUB BURTACES REQUIRING SURGICAL TREATMENT.

Case I. Pendulous Tumour of the Nympha: Excision. A. J., aged 31 years, a small made, pale looking woman, married, was admitted, under my care, in the General Hospital, December 22nd, 1854, suffering from the prosence of a pendulous growth continuous with the nymphr.

History. About eight years since, she first noticed an enlargement, about as large as a marble, situated in the left nympha. This was very distinct at first, but subsequently the adjacent lip and intervening space partook in the growth. The increase in the parts was gradual until within the last two years, when a more rapid change became established, and she began to suffer inconvenience from the deformity. About two months since, several ulcerated spots having become formed, from the friction of the parts in walking, hæmorrhage to an alarming extent, and frequently repeated, drove her unwillingly to the hospital. She states that she has never led an irregular life, and has never been the subject of venereal disease or of gonorrhoea. At fourteen, she acknowledges to having commenced intercourse with the opposite sex, at which period she also commenced menstruation, and has continued to experience ever since the utmost regularity in regard to that function. At serenteen she married, but has neter been preguant.

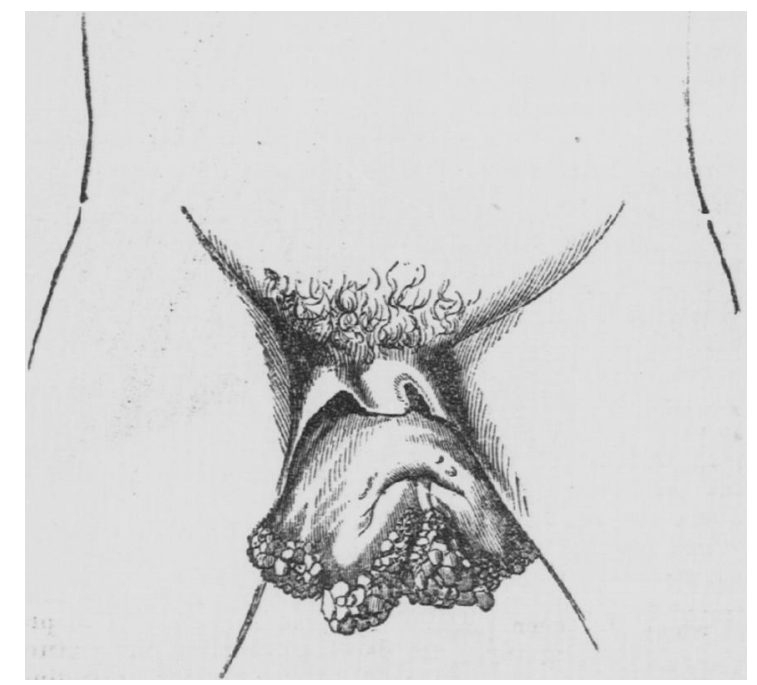

Fig. 1. Pront View of Tumour.

Upon examination, a fleshy mass is seen to be pendulous from within the external labia. It hangs down between the thighs for a distance of fire or six inches, covering altogether the vaginal orifice. Upon the patient's lying down, the tumour can be separated into a right and left portion, and the urethral and vaginal orifices can be then seen. It is evident that the enlargement consists of the nymphr connected together superiorly by the thickened commissure of the prepuce and clitoris, from which points springs the pedicle supporting the growths on either side, so as to cause them to look like a single tumour hanging down betreen the thighs. In colour, its appearance is a pintish 
Jellow. The sides and opposed portions are smooth, but its free surfaces and most dependent parts are divided into various lobes, and these again into lesser ones, resembling fiattened tubercles, varying from a few lines to half an inch in breadth. The left half is larger than the right, and presents on its most dependent part some points in which recent ulceration has been going on, and from which the hremorrhage alluded to occurred. Measured in their widest extent, the altered nymphr compass a space of between seven and eight inches. The pedicle is about two inches wide, by an inch in thickness. The pulsating cords of large ressels can be felt passing through to the mass below, and the venous trunks can be distinctly seen. Viewed from behind, the pediculated character of the disease is well marked, and the limits of each nympha are very distinct, those of the left forming four-fifths of the whole mass. Whilst under examination, I noticed that its colour varied, becoming paler, and then more red. It did not appear to diminish in size. There was an offensive odour exhaled from the parts generally.

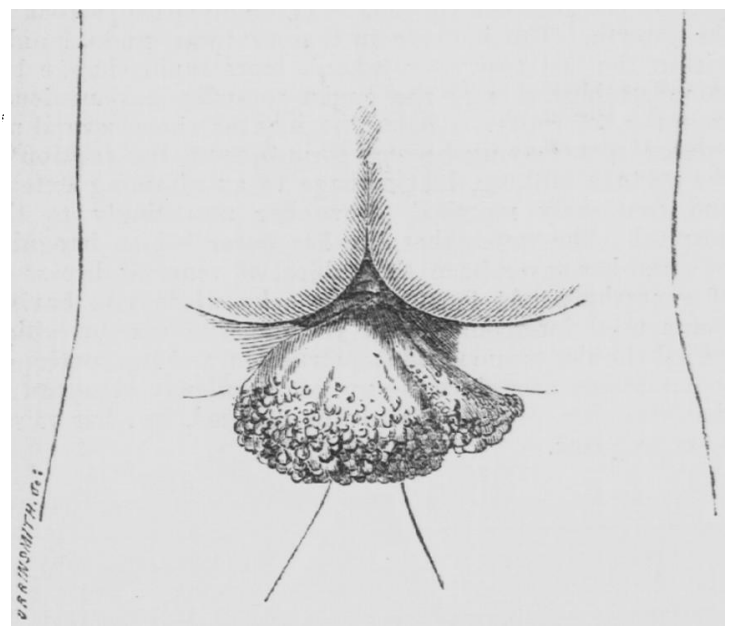

Fig. 2. Rack View of Tumour.

Having waited for the cessation of the menstrual period, on January 10th, under the influence of chloroform, I proceeded to remore the growth. I first transfixed its base by passing a double ligature through the centre of cach nympha, and then strangled the mass by tying the circle of ligatures, grooving the thickened structure of the pedicle between the points of entrance of the needles, in order to facilitate the tightening of the cords. The knife was then passed about a quarter of an inch below around the growth, and its removal completed. Three or four vessels required ligature, but the hæmorrhage was perfectly controlled by the means adopted. The parts were dressed with cold water, and the patient recorered without any drawback.

She left the hospital February 9th. The wounds were healed. The left external labium was a good deal infiltrated from adjacent irritation.

A few days after the operation, I exhibited the parts at a meeting of the Medico-Chirurgical Society of Queen's College; and their particular examination having been referred to my friends Dr. Heslop and Dr. Wade, I have now the advantage of adding their report.

The tumour, which was bilobed, was not encysted, but its structures were continuous with those of the parts from which it sprang. It therefore came strictly under the definition of an outgrowth. At those parts where its two surfaces came into opposition, it was smooth; but the free surfaces were covered with verrucæe of similar structure to the body of the tumour, and were outgrowths from it. On section, it appeared glistening and moist, from the free exudation of an opaline fluid, which was found to be highly albuminous. In appearance it was like udder, or edematous cellular tissue, of a yellowish white colour, and intersocted with slender white bands. It was solid, especially near the surface and towards the centre, whence most. fluid exuded.

On microscopical examination, the fluid was found to contain fine molecules, apparently of oil (to which its opaline appearance was probably due), a few fragments of fibrous tissue (in which nuclei became apparent on the addition of acetic acid), and cells, which were colourless and transparent, containing nuclei of small size, in proportion to that of the parent cell. The cells were generally polygonal in outline, except some which were prolonged and fusiform, and seemed to be undergoing a fibrous transformation; in fact, every gradation between perfect cell and perfect fibre was observed. A small quantity of yellow or elastic fibrous tissue was also discovered. The structure of the verrucous outgrowths was in all respects similar to that of the parent growth, but in them the fibrous seemed to predominate over the cellular elements, and they were much drier on section.

Case II. Pendulous Tumour of the Nymphae: Excision. E. S., aged 29 years, married, a fair haired, delicate, worn looking woman, was admitted, under my care, in the hospital, on August 13th, 1855, suffering under numerous fistulæ around the anus, and from a pendulous outgrowth of the nymphr.

History. She has been married five years, but has never been pregnant. About two years since, there appeared a general enlargement of the inner lips of the vulva. This gradually increased up to the time of her admission into the hospital. Latterly ber health has been very much broken, and she has become the subject of numerous abscesses about the anus. The menstrual discharge has been constant. She has lived a regular life, and has never contracted renereal disease or gonorrhoa.

On examination, a pendulous growth is seen hanging down from between the outer lips of the rulva. 'This is continuous with, and arises out of, the nymphr. It is as large as a man's closed hand, presenting an appearance identical in all respects sare in size with that of the case previously narrated. The integuments about the anus are much thickened, and numerous fistulæ communicate with the rectum, and add to the patient's misery by the discharge of fæces.

Aug. 20th. I removed the outgrowth, under the influence of chloroform, by means of the scalpel and ligature, as in the previous case. No hæmorrhage of consequence resulted, and the patient made a good recovery, under the influence of generous living and cleanliness.

She left the hospital August 20th, the parts quite healed, and the fistulæ nearly dried up.

On section, the tumour presented appearances altogether similar to the preceding.

CASE III. P'endulous Tumour from the Mruco-cutaneous Surface of the Anus in a Man: Excision: Formation of a Second One many Years after the First: Excision. J. W., aged 37 years, married, a tall, well built, muscular subject, a gas-worker by trade, was admitted, under my care, in the General Hospital, May 19th, 1856, with a pendulous growth attached to the muco-cutaneous surface adjacent to the left margin of the anus, and hanging down from a point exactly corresponding to the fold of the buttock of the same side.

Ilistory. About seventeen years ago, the patient observed a small pea-like swelling on the left natis, a short distance from the margin of the anus. This was not painful. It increased, however, in size, and gradually attained a magnitude as great as that of the tumour which he now carries. Its situation almost entirely prevented. him from sitting down, and, when he did so, he was compelled to throw the weight of his body wholly on the opposite side. After the tumour had existed for five years, he was admitted a patient in the North London Hospital, under the care of Mr. Quain, who removed the growth by ligature. It is now twelve years since the first tumour was remored. From that time until about seven years since, he enjoyed uninterruptod good health. About this 
latter period, he perceired another small wart-like growth occupying as near as powible s sito sbout ono inch abovo the cicatrix of the tumour which had been remored. This grow much in the same as the first growth had done. He worked on, however, and would probably have continued doing so, had not an attack of hremorrhage from an ulcerated spot on the surfice next the buttock compelled him to apply to Mr. Cley, surgeon, of this town, who sent him to me for operation without delay.

Upon examination, the tumour is seen hanging down in the situation described. It is somewhat square in shape. It measures eight inches in its longest, and five in its shortest diameter, and is about three inches in thickness. Its pedicle, which is smooth, and composed of muco-cutaneous structures, measures two inches in length, by the came in breadth. Above, the pedicle is lost in the continuity of the parts adjacent to the left margin of the anus; and below, it terminates by a well defined margin in the irregular surface of the growth itself. The free aspect of the tumour presents a well marked warty appearance. The surface is first of all divided into six or more lobes of large size, separated from each other by interrening furrows, more or less deep. Each lobe is made up of many smaller ones, which are closely packed together, but can be separated from each other by the exercise of a little pressure. The colour varies in intensity in different parts; generally it is of a pinkish hue; but this is modified by the crusting of discharge, of a peculiarly offensive character in some places. The surface applied against the buttock is much smoother in appearance, and almost altogether deroid of the warty character. In its centre, a ragged ulcerated spot marks the situation of the hremorrhage. The patient informed me that he had lost a very large quantity of blood previous to his admission, and felt weak in consequence. In other repects, he felt well, and had never experienced any pain, nor indeed any annoyance from the tumour, sare that of inconvenience.

He has been married for eleven years, and is the father of five children. He admits having had chancre and bubo twenty years since- a confession borne out by the presence of well marked cicatrices at the present time.

The drawing here given most accurately represents the sppearance presented by this tumour.

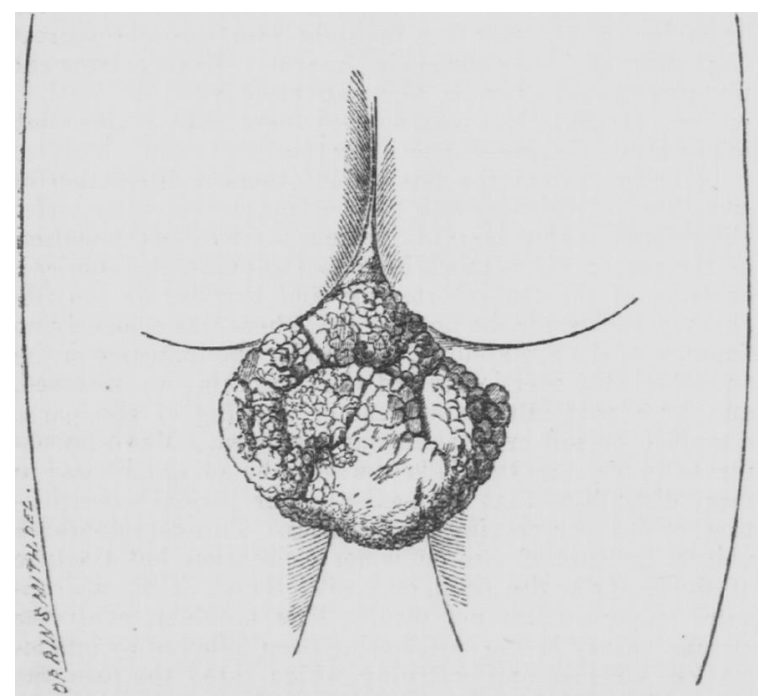

Fig. 3. Pendulous Tumour of Anus.

Nay 28th. Under the influence of chloroform, I proceeded to remove the disease. Having enveloped the growth by a napkin, I was enabled to make tense the pedicle, and proposed to myself to incise the mass by an elliptical incision at the base, without the previous application of a ligature, as I thought I should readily control the hrmorrhage in this situation. I had scarcely, however, marked out my incisions, and was proceeding to pass the knife through the interrening structures, when a rush of blood took place, 80 formidable that I felt at once the necessity of passing a ligature so as to encircle the neck above my incisions. This enabled me to control the bleeding for the moment, whilst I separated the remaining attachments of the growth. The ligature, owing to having small hold, slipped, so that, covering their mouths by my fingers, I was now compelled as quickly as possible to secure eight or nine vessels, several as large as an adult radial artery, by separate ligatures. All bleeding ceased after this, and the patient was removed to bed.

He was discharged, with the wound soundly healod, July 4th.

The tumour, on section, presented the same appearances with those described in the first case. The parts were, however, more dense and thickened, and contained less of the characteristic fluid.

RExarks. The preceding cases afford good illustrations of that kind of tumour which has been so aptly styled by Mr. Paget (Jectures on Surgical Pathology, vol. vi, p. 21) a cutaneous outgrowth; that is, a lengthening, as it were, of the cutaneous or muco-cutaneous surfaces of the body, in which the materials of the original part are maintained, being at the same time increased in dimcnsions and altered in arrangement, but still continuing in structure identical with that of the parts from which it grew. Eminently innocent in character, these growths clain the interference of the surgeon chiefly on account of the painful inconvenience to which their situation gives rise, or to the hæmorrhage which their ulcered surfaces almost invariably, after long continuance, occasion. Though not encountered in this country with a frequency or magnitude comparable with the fibro-cellular hypertrophies which abound in tropical climates, and with which they would appear to be closely allied, they are yet by no means uncommon. The case recorded by Mr. Lawrence (Med.-Chir. Transactions, vol. xvii) shows the size that may be sometimes attained by them in this country. In Guy's Hospital, one was removed, growing continuous with the right labium: it is recorded in the Lancet for 1827 , and it also attained an enormous size.*

The most constant situations for these growths are the muco-cutaneous surfaces of the female parts of generation. The enlargement may belong to oply one labium, or it may assume the character of a symmetrical hypertrophy of the nymphr, involving the clitoris and its prepuce. More rarely such complaints are met with in the male subject; and Mr. Paget (Surgical Lectures, vol ii, p. 106) records an instance in which he removed from a man's nates one of dimensions so large, that its base covered the whole regicn of the glutæi muscles. The muco-cutaneous surface around the anus would appear to be in the male, for these growths, what the pudendum is in the female. Still amongst men they are of extreme infrequency, so much so that $I$ have not been able to discover a record of a pendulous growth altogether similar to the one I have described as having been observed in the male subject.

The surgical points which present themselves for romark are, firstly, as to the diagnosis, and secondly, as to the treatment and its results in these cases. The generic characters of the disease are as follows :-

1. A growth unaccompanied by pain.

2. The formation of a tumour continuous with the structures supporting it, of a pendulous character.

3. A warty and tuberculated appearance of the free surfaces, resulting from an hypertrophied condition of the papilla of the skin.

4. A consistence more or less elastic and soft to the touch, a colour varying from a brown to a reddish pink, and an odour of a peculiar and offensive character.

The painless and rapid increase of these growths, their

- Cases more or less similar may be found described in the Lancet, vol. il, 1846, p. 75; vol. i, 1850, p. 604; vol. i, 1855, p. 04, 
chaticity, and their pendulous charieter, will suffice to dietinguich thom from malignant ones in the same situation. Their comparative frequency, aleo, will be an additional means to lead to an accurate diagnosis. From pendulous adipose tumours, not uncommonly met with about the ame parts, especially in the labis externa and inner aspect of the fold of the groin, they may always be rocognised by their peculiar characteristic of surface, before alluded to, by their more irregular form, and by their more rapid growth. The adipose tumour may, it is true, bo found pendulous in the situation referred to, but, comparatively speaking, rarely; still less frequently does its surface ulcerate; and never, so far as my experience enables me to judge, does it assume a papilliform condition.

The specific characters of the disease in the male sex simply belong to the situation in which it developes itself - the margin of the anus-and to the tumour itself being of a denser character.

The result of my experience and observation is, that these tumours have little or no liability to return. The recurrence of the tumour in the case of the man must not be confounded with a return of the disease, inasmuch as it originated from an adjacent portion of skin, and not from the cicatrix, as is usual in cancerous growths. The explanation of the circumstance depends, it appears to me, on the fact of there being a persistence of the same exciting cause which led to the formation of the disease in the first instance.

The necessity for surgical interference is generally decided by the feelings of the patient. For a long time annoyance and inconvenience are alone experienced. There is no pain whatever. At length, from increasing bulk, the surfaces either rub against each other, or against adjacent parts ; ulceration not only gives rise to pain and offensive discharge, but it also occasions alarming hæmorrhage, which, if not arrested, would be sufficient to destroy the patient's life. When, therefore, the deciding for or against operative measures rests with the surgeon, the sooner he recommends interference the better. The sad condition to which the second case, E. S., was reduced-that of fistulæ about the anus-points to the value of an early operation in these cases, and shows more than anything can the debilitating influence which such complaints exercise upon the constitution.

In conducting operations for the removal of such growths, the application of a ligature previous to their separation by the knife should never be dispensed with. They are always largely supplied by blood-ressels, and if this precaution be neglected, the loss of an amazing amount of blood will certainly endanger the recovery of the patient. The tumours should not be left to slough off, but should be cut through below the ligature; after the mouths of the arteries have been tied, this may be removed, and the reins will not then give rise to any more bleeding than what a little cold water will suffice to restrain.

The results of operations in these cases may be deemed, therefore, most satisfactory. The wounds heal rapidly, whilst the patients themselves recover the strength they had lost, and are free from that mental anxiety which never fails to accompany the derelopment of this disease.

\section{第ospital Galeamings.}

AXPUTATION AT THE HIP-JOINT.

MB. Corirna performed this important operation in the Iondon Hospital, in March last, on a woman about forty years of age, in weak health, who had a large tumour imbedded in the muscles of the right thigh, and reaching nearly to the pubes. Chloroform having been administered, the main artery was compressed at the pubes, and the thigh acutely flexed. Mr. Curling then made a large posterior fiap, cutting rapidly from without in rarda. Two of the chief branches of the gluteal artery haring been secured, and a large sponge applied to the flap, the thigh was depressed, and an anterior flap being made, the bone was disarticulated. This mode of proceeding was adopted to prevent the loss of blood, and not more than four or five prevent the lost in the amputation. After the bleeding vessels had been tied, the two flaps were brought together with numerous sutures, and the surfaces were kept in close contact by a large quantity of cotton wool applied on the outside covered with lint, and well secured with strapping. The stump healed farourably, and at the end of two months the patient was sent to the sea-side for the improvement of the patient was sent to the sea-side for situated beneath the rastus externus muscle, and rested on the outer part of the femur, extending close to the bone as high as the great trochanter. It consisted of masses of brain-like matter, large coagula, and numerous imperfect cysts. The surface of the femur in contact with the tumour was abraded and very vascular. The morbid growth exhibited the microscopic characters of encephaloid cancer. Her health is improving, and, up to the present date, there have been no symptoms of a recurrence of the disease.

UNOSUAL CASE OF INJURY OF THE HIP : FRACTORE WITH MODIFIED OB MUYFLED CREPITUS : DETECTED UADER THE EFFECT OF CHLOROPORM.

Mr. SKEY has had a somewhat remarkable case of fracture in one of his wards, which seemed very puzzling at first, but which is now progressing very favourably. The accident was so peculiar, yet of such an eminently practical and suggestive kind, we deem it worthy of notice.

The case is that of a boy, otherwise healthy, admitted into Harley ward, with a singular condition of the left hipjoint, and the following history. It seemed that he had been riding in a cart, and fell over, pitching heavily on the ground, but he was taken up, placed in the cart, again sitting up, and taken home; he hobbled about for six or seven days, but then fell again, and observed something to give way in the neighbourhood of the hip-joint. He still made nothing of the accident, but walked with a stick for not less than three weeks more in this state. He was ultimately forced to give up, and come to hospital. Mr. Skey saw him very soon after admission, and, on making a careful examination of the case, he found the left leg to be half an inch shorter than the right, everted, and the great trochanter obviously turued backwards. Much excitement was now caused as to its being an undetected dislocation, whereas Mr. Skey had been assured there was no dislocation of any kind. Several surgeons saw the case; some considered it to be fracture of the ossa pubis, others a dislocation of some kind. Mr. Skey had the boy placed carefully under chloroform, so that he could make a thorough examination of the parts; when, in addition to the points just noticed, eversion of the foot, shortening, and turning of the trochanter backwards, he noticed that there was evidently no fracture of the acetabulum, that under the influence of the anæsthetic the eversion ceased, the shortening was removed, and by a particular movement or shaking of the parts, a muffied or soft crepitation was perceived. Mr. Skey observed to his class that it is unwise to be going half way to meet difficulties that only exist in our patient's imagination, or our own craving for novelties. This case appeared neither fracture of ossa pubis nor dislocation, but fracture of the femur at the neck, only with the thick fibrous capsule or periosteum not torn. This accident, after the original injury in the cart, having been followed by inflammation, effusion, and softening, which eased the pain, the boy hobbling about as described, but the parts ultimately yielding and breaking right off when he was brought to hospital. Mr. Skey said the feel was quite different from the crackling of egg-shells sort of sound in the crepitus of old patients with this accident.

June 20th. The boy has gone on very well, with a graduated screw to the splint and perinesal bandage; the patella is normal; the erersion is gone; crepitus gone. 